\title{
Graduate Education and the Disappearance of Humanism
}

\section{Neal Lane}

This is an edited version of a talk presented at the Mathematical and Physical Sciences Workshop on Graduate and Post Doc Education held in Arlington, Virginia on June 5, 1995.

In 1931, Albert Einstein said, "Concern for man himself and his fate must always form the chief interest of all technical endeavors, concern for the great unsolved problems of the organization of labor and the distribution of goods--in order that the creations of our mind shall be a blessing and not a curse to mankind. Never forget this in the midst of your diagrams and equations."

Einstein takes us back to our fundamental values as guidance in finding our compass heading. Science and technology are neither inherently good nor bad. Rather it is what we do with them that makes them so. Fertilizer and fuel oil are at least benign, at best beneficial, and at worst destructive.

November 1989 marks the official end of the Cold War. A most interesting articulation of this moment in history appeared in the preface of a 1994 report from the National Research Council on the changing environment for the physical sciences and mathematics, "Throughout the Cold War, the nation was in a kind of metastable state with a known enemy and a strong rationale for doing research to stay ahead of that enemy. That state was nowhere near equilibrium; it was just a pause in the flow of history. With the end of the Cold War we now seem to face constant, somewhat chaotic, and confusing change.... If this argument is accepted, the transition out of the Cold War marks the resumption of historical change."1

If this is such a time-a time when the ordinary course of historical perturbations unsettles our sense of unity in the absence of a common foe, and a time that derails our rationale for doing research to stay ahead of an enemy-if this is such a time, then how do we find the right compass heading for the nation and for science, and who will lead?
In answer to these questions, Einstein would have answered that the compass heading is concern for humanity and its fate; the leaders, among others, are those very scientists and engineers, the creators of fertilizers, the makers of technology, the inventors of genetic engineering, and the magicians of superconducting materials.

We abdicate our responsibilities as citizens if we as scientists and engineers do not understand our science and technology in the larger context of humanity and its "great unsolved problems." In the United States, those problems are numerous. In other parts of the globe, they are myriad. We face urban physical and social ills, the dilemma of providing jobs while technological advances and industrial downsizing shrink the demand for workers, the need to sustain the vitality of our global habitat while supporting sufficient economic growth to maintain expanding populations, and many more.

An important component of graduate science education needs to be devoted to this larger context in which science and technology have such strong influence. We abdicate our responsibilities as teachers and mentors of the next generation of scientists and engineers if we do not portray their task as larger than data banks and lab procedures, and more important than publication in prestigious journals. The sophisticated knowledge and esoteric understanding in which all of us delight is important, but it is not enough.

The public looks to science for wisdom

Material Matters is a forum for expressing personal points of view on issues of interest to the materials community. in finding solutions to real world problems, but our skills and knowledge can provide that wisdom only if they are grounded in strong values and goals: the universal dignity and well-being of humankind. That is taught by one's own example and by active mentoring.

There was a time when training in the sciences was an integral component of the education of a poet, or philosopher, or historian. Leonardo da Vinci and Galileo were schooled in the arts, the humanities, and the sciences. They are often the figures that contemporary leaders return to for the essential wisdom, the fundamental understandings, the underpinnings of directed thought and action. They are the thinkers that we still quote and requote.

As society advanced and entrenched, science was separated from history, literature, and philosophy-until C.P. Snow labeled scientists and engineers a separate culture from the humanists. More serious, today, is the separation, real and perceived, of science from society itself.

This separation, which reflects both isolation and autonomy, nullifies a great many contributions that scientists and engineers can make to our larger societal goals. It also appears to exonerate us from many of the responsibilities we should carry in our society.

To put it a bit too simply-the scientists' opinions and contributions are not as widely sought and credited as they should be. And the scientists, for their part, are not as ready to offer their services to society as perhaps would be ideal.

The noted historian of science, Evelyn Fox Keller, speaks provocatively of values and goals, and science. She says, "We have developed scientific methods and techniques to change the world without asking what we would change the world to. We never acknowledged we were making choices that could change the world."

The point is clear. Skills and knowledge, if grounded in our values and directed by our goals, can bring us to wisdom. Without strong underlying principles, those skills and that knowledge can as easily bring us to chaos and misdirection as they can bring us to benefits and beneficence.

It seems to me that we ignore part of our social responsibility as scientists and engineers if we think that science and technology, directed primarily by their own internal drivers, can replace economic and social goals based on a shared structure of values and moral judgment.

The value system that Einstein articulateci in 1931 in his talk at Cal Tech had to do with honoring human dignity and social equity. I'm sure that by now he 


\section{MKS Materials Delivery \\ Systems • Components • Solutions}

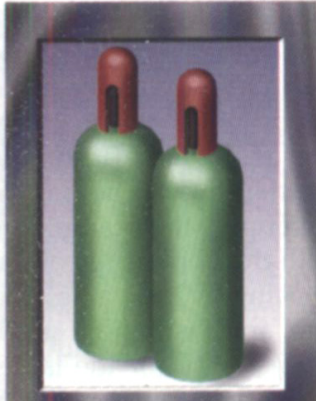

Gases

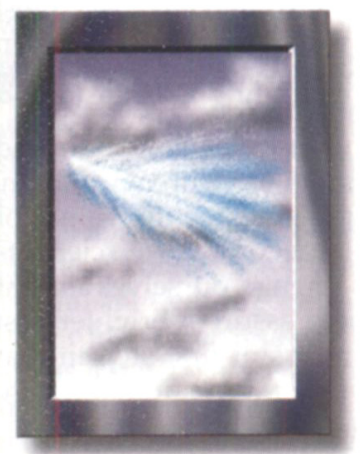

Vapors

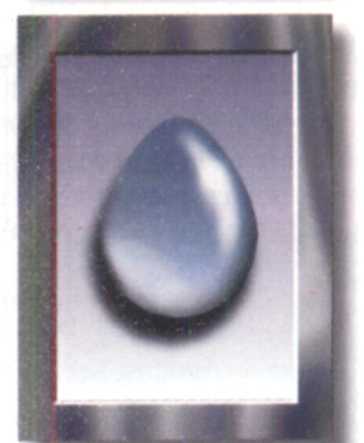

Liquids

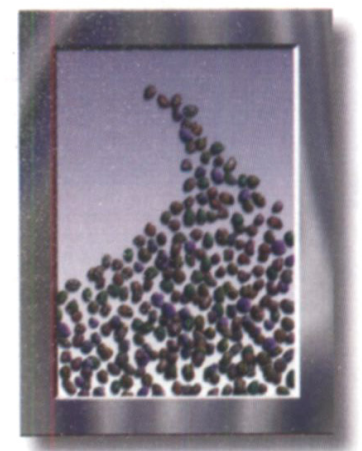

Solids
MKS Vapor Source MFC's employ a pressure-based measurement and control technique to deliver source vapor without the need for a carrier gas system. 1150 and 550 Series MFC's feature a wide operating temperature range $\left(30^{\circ} \mathrm{C}\right.$ to $150^{\circ} \mathrm{C}$ ) and can therefore deliver a variety of vaporized liquid source materials into low pressure systems.

Direct Liquid Injection (DLI) sub-systems utilize a micropump, vaporizer and electronics control unit to deliver 0.001 to $10 \mathrm{cc} / \mathrm{min}$ liquid in a smooth pulse-free manner. Liquid Precursor Delivery Systems (LPDS) are integrated/ configurable systems that provide a custom delivery solution using a positive displacement metering pump and vaporizer.

Both the MKS Liquid Precursor Delivery System and the Type 1150 MFC can effectively deliver dissolved or heated solid sources. In Copper CVD processing, the LPDS is used to deliver $\mathrm{B}$-diketonate $\mathrm{Cu}^{\prime \prime}$ by dissolving the solid material in a solvent such as isopropanol. Sublimed solid sources can be delivered directly without the use of a carrier gas with the MKS Types 1150 and 550 MFC's.

\section{Worldwide Customer Support}

MKS materials delivery products are supported by a worldwide network of dedicated field sales and service engineers and applications specialists. 
would have added the cross-generational preservation of the planet while seeking equity for all human beings. It has often been a science and technology in the absence of these values that has widened our social inequities and has accelerated environmental degradation.

Just as none of us are to blame individually, all of us as a society are to blame. Economic growth driven by science and technology can only serve the greater good if our values and goals move us toward that objective. This should be the overriding context and the unifying principle of a new graduate education.

The United States is now the only super power in the world. This is far different and in many ways more complex than being the only democratic super power. In the past, our task was almost singularly to contain the threat of Communism and to keep alive the principles of democracy.

Today, as the only super power, U.S. leadership should be more comprehensive and far-reaching. We should be the advocates of global economic and social opportunity, political freedom, and sustainable development. Scientists and engineers have an even broader portfolio of opportunities and responsibilities. Graduate education in science and education should reflect these. Instead of training our graduate students to replicate their mentors we should educate them to the myriad opportunities that training in science offers. And we should instill in them a sense of responsibility for the larger society. Does this happen? Of course it does, but perhaps not as often or as visibly as would be ideal.
Science and technology have become such integral parts of society that scientists and engineers have actually imagined and constructed the world in which we live. We must not isolate ourselves from societal concerns. The research community is needed in the large societal debate on values and goals for our future. Informed debate on public policy, the prevention of violence, the education of current and future generations, high value jobs, and competition in global markets require that science and technology become a more integral part of our national fabric. And the research community is the key to that integration.

The role of the scientist and engineer, however, is far broader as Einstein had advocated and as the British Nobel Laureate Sir Peter Medawar eloquently described. In Medawar's slim but classic 1979 volume entitled Advice to a Young Scientist, he wrote, "Many young scientists hope that the science they come to love can be the agent of a social transformation leading to the betterment of mankind; accordingly they lament that so few politicians are scientifically trained and that so few have a deep understanding of the promise and the accomplishments of science. These lamentations betray a deep misunderstanding of the nature of the most exigent problems that confront the world: the problems of overpopulation and of achieving harmonious coexistence in a multiracial society. These are not scientific problems and do not admit of scientific solutions. This does not mean that scientists are confined to being shocked spectators of events or political dispositions that threaten the well-being of nations and ultimately mankind; scien- tists, as scientists, will find that they have necessary and distinctive contributions to make to the solution of these problems." 2

Although Medawar's advice is to young scientists, I do not think he meant to exclude any of us. In fact, I think he envisioned our generation to be part of the solution-teaching by the example we set, mentoring with the knowledge of our experience, influencing by the values and goals we articulate, and instilling a steadfast sense of responsibility for the larger society. If we expect the United States to provide visionary leadership in the next century, we scientists and engineers must not be content with the sound of our own rhetoric. We must instead be inspired by Medawar to enter the fray.

In the long run it is not enough to tend our own values and those of our children. We are all responsible for the values of the society at-large, and if we scientists and engineers engage ourselves in that task we will help assure a brighter 21st century. An important first step in that process will be to return humanism to graduate education in the sciences.

\section{References}

1. "Beginning a Dialogue on the Changing Environment for the Physical and Mathematical Sciences," Report of a Conference. Commission on Physical Sciences, Mathematics, and Applications. (National Research Council, National Academy Press, Washington, DC, 1994) p. iv.

2. Advice to a Young Scientist, P. Medawar, (Harper \& Row Publishers, New York, 1979) p. 104.

Neal Lane is the director of the National Science Foundation.

\title{
New Videotape \\ "The Golden Age of Crystal Defects"
}

\author{
Arthur S. Nowick, recipient of the 1994 MRS Turnbull Lectureship \\ Price: $\$ 40.00$ MRS Members \\ $\$ 46.00 \quad$ U.S. List \\ $\$ 55.00 \quad$ Non-U.S. \\ Order Code: VHS-15-B \\ Available from Materials Research Society \\ Contact MRS Publications for Details \\ (412) 367-3012 \\ Fax: (412) 367-4373
}

